\title{
Extramural Epidemiology and Genetics Program
}

National Cancer Institute

\section{Source}

National Cancer Institute. Extramural Epidemiology and Genetics Program. NCl

Thesaurus. Code $\mathrm{C18788.}$

The Extramural Epidemiology and Genetics Program is the extramural equivalent of the $\mathrm{NCl}$ Division of Cancer Epidemiology and Genetics. 